\title{
Public Trust in Information Media of the Spread of Covid-19
}

\author{
Guirado Schröck $^{1}$, Steuble Falkesgaard ${ }^{1}$ \\ ${ }^{1}$ Mapúa University Manila, Philippines \\ Received: January 5, 2021 \\ Received in Revised: January 27, 2021 \\ Accepted: February 8, 2021
}

\begin{abstract}
This article discusses Public Trust in the Information Media for the Spread of Covid-19. Framing the news is necessary to maintain a positive perspective from the public towards the government. This will be an important action for the government to solve the pandemic because collaboration between the community and the government is needed. There have been efforts made by the government in fighting COVID-19 until finally guaranteed public trust should be the main goal of online news framing in the current pandemic situation. The general public should be able to sort out which news is right and which is wrong so that we do not have bad speculations about the people who are victims of this Covid-19. Framing the news is necessary to maintain a positive perspective from the public towards the government. This will be an important action for the government to solve the pandemic because collaboration between the community and the government is needed. There have been efforts made by the government in fighting COVID-19 until finally guaranteed public trust should be the main goal of online news framing in a pandemic situation.
\end{abstract}

Keywords: Public Trust, Information Media, Covid-19 Spread

\section{Introduction}

Inaccurate news or information and even hoaxes occur, so that it is difficult for the public to get information that has a source of truth. This can influence the public to believe again in public information. With this, usually the information conveyed does not have several elements, such as who was the first person to disseminate the information, and the information conveyed does not have clear explanatory data and can even be manipulated that easily to create fear in the community. To sort out public information that provides truth and good elements, this also makes our duties and homework together as young people and young people of the nation, in doing good things as well as regarding super dubious public information, the clarity and truth can be ensured.

It is difficult to solve this problem in order to return the tangled thread to its original state. Because many various groups use social media access to find information, create information, disseminate information, immediately see from the province of the Bangka Belitung archipelago itself, and we can even access the whole world regarding this public information. We can meet various political issues and even criminal issues at the same time in various media, as for issues that involve the entire community such as unrest in poverty, hot new issues such as the passing of the law, which can trigger pros and cons. contra among citizens and the issue of the corona virus which is widely discussed and a lot of public information that is widespread in the community

Information is an effort to create transparency for the public to find information that is accurate on a scale so that the process of conveying movements that have been carried out by the government or a group of people is carried out, in order to provide public confidence in the information obtained from the public, then this can form a new concept towards building 
public trust throughout the world. So with this the author wants to provide new ideas on how the concept of building public trust is, so that we can trust the information again and can ensure that the information can truly be trusted by the wider community, with this there are two concepts that become reference and what the writer offers to this paper, namely transparency and accountability which are used as a reference in the concept of building public trust to get more confident and reliable information.

Information is something that is fundamental to knowledge, and people who are educated and knowledgeable are people who experience empowerment and therefore can participate in population affairs, social development, and progress. Transparency is one of the principles in good governance, aiming to create mutual trust between government and society by providing information and guaranteeing ease in obtaining information. Transparency is needed so that public oversight of state administration can be carried out objectively. For this reason, it is necessary to provide information through an information and documentation system that can be accessed easily on the pattern of formulation and content of laws and regulations and public policies and their implementation by each state institution.

Website is a manifestation of the principle of transparency (Meijer, 2009). Government websites provide great opportunities for innovation in the public service sector. These innovations need to be diffused to support the implementation of effective and efficient public services. Then the second is accountable, which is a term used to describe the level of accountability of a person or a certain institution related to its administrative system. And the responsibility of a public agency in order to convey information that actually exists and can be accounted for in accordance with the law on public information disclosure. So with this it can make public trust in building public trust in the future. According to experts, accountability in public institutions can be divided into five parts, namely: Legal Accountability and Honesty-This accountability is an accountability related to law enforcement activities and also the norms of honesty shown by not committing various kinds of abuse of power and authority owned.

\section{The Role of Media in the Covid-19 Pandemic Era}

One of the functions of the mass media is to serve as a discourse for the formation of public opinion. Whether through news, editorial comments and articles published in newspapers, it raises different opinions from the public. In the framework of forming public opinion, the mass media generally carries out three activities at once. First, using political symbols (language of politics). Second, carry out framing strategies. Third, perform the function of the media agenda (setting function). That is why the press has an important position in a country, namely as a four branch of government (the fourth pillar of democracy). The position of the press as the fourth pillar of democracy is because the press has a role to play in shaping public opinion.

During the pandemic, the audience and the public again face the same dilemma, namely doubts about the information provided by the media. The process of selecting issues, priming and framing by the media often makes the public not necessarily believe what is presented by the media. This paper attempts to describe the factors that cause public trust in the media during a pandemic to change. Even though the media consumption behavior is high, the trust in the media is still under the public's trust in scientists and medical personnel who they consider as a reference for information.

Media has a very important role in the circulation of information related to the Covid-19 outbreak, both from one region to another and from one person to another (Ahmad \& Murad, 2020). That means, the role of the mass media is vital in overcoming the Covid-19 outbreak. 
The mass media has positive things if the information disseminated is used as it should. For example, information on the dangers of being exposed to Covid-19, how to identify the symptoms of Covid-19, how to avoid being exposed to Covid-19 with a Clean and Healthy Lifestyle, and being able to find out how many people have been affected by Covid-19 in their respective areas.

In the early days of the pandemic, the media became the main reference for the public to seek information about this new outbreak. Mainstream media is the main reference for the community because from the perspective of the news search process to presentation, it has rules for both print media, electronic media and online media. A number of prominent media names that have long been engaged in journalism have become the choice of the public. However, this global pandemic has created a stigma that is much faster than its handling measures, this has made people even more confused and trying to find alternative sources of information that are believed to be enlightening. Consumption behavior has begun to change from relying on mainstream media, a number of alternative media has also become a reference to social media.

In the search for alternative information, clashes often arise between what is happening in one media and another. Because people during a pandemic don't just consume one media as a reference for information. The tendency to consume information that is easy to understand and easy to apply in everyday life related to the pandemic has attracted people to choose a media.

The information provided can help the public to find out earlier about the Covid-19 outbreak. In addition, the information disseminated can also help the government to create statistical data on the distribution of people who are positively affected by Covid-19, so that they can be more careful with the local people who live there. The mass media can also assist the government in disseminating information about the Covid-19 outbreak to make it faster, more accurate and reliable.

The role of the mass media is also very important to assist the government in disseminating information about the Covid-19 outbreak (Zhao et al., 2020; Liu et al., 2020; Hamzah et al., 2020; Liao et al., 2020; Pan et al., 2020). Therefore, we as ordinary people should be able to sort out which news is right and which is wrong so that we don't speculate badly about the people who are victims of Covid-19. Haven't we as Muslims have been taught how to keep tabayyun on the news we get.

\section{Level of Public Trust in Media}

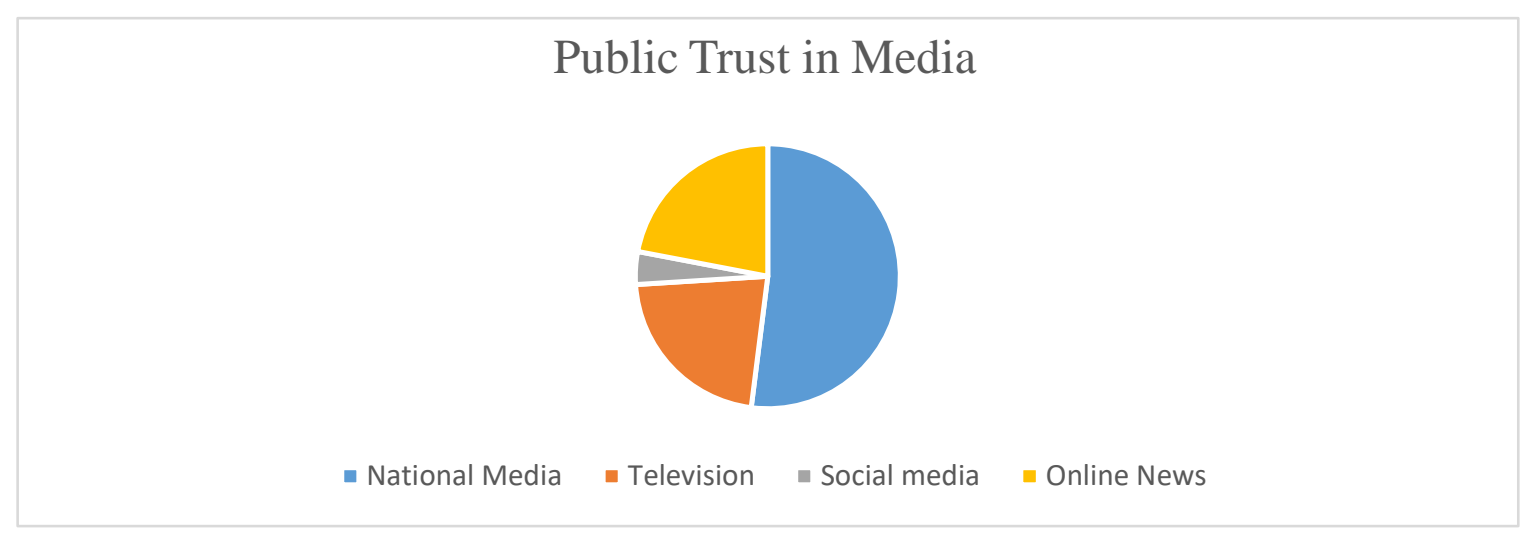

Figure 1. Level of Public Trust in Media 
The pros and cons of the way people understand Covid-19 are reflected in the excitement of communication on social media. This is due to the lack of comprehensive information due to disruption of public communication. Moreover, the length of the Covid-19 pandemic has exacerbated disturbances in public communication.

Public trust in media in several countries has decreased along with the rise of social media platforms and search engines (Newman, 2009; Kane et al., 2014; Laroche et al., 2012). Edelman Tust Barometer's 2018 report shows that of the 28 countries surveyed, only six have a level of trust in the media above $50 \%$. The rest experienced distrust of media with a trust level of below $50 \%$.

The media is still a reference for the public to seek information. This is reflected in the $68 \%$ public trust in the media. This figure puts public trust in the media in second place after China, which has a confidence level of $71 \%$.

The rapid advancement of telecommunication technology has influenced the public in receiving information. Previously, to get news, someone had to look for news sources, but now information has automatically entered the social media they have. Unfortunately, much of the information that comes to social media is in the form of false information to fake news whose sources and contents are not clear.

\section{Efforts to Increase Public Trust in Information Media}

Public trust in the mainstream mass media must be restored immediately. This is because the mainstream media has a very strategic role in preventing and combating hoaxes that have been rife lately. The first step must be taken by the mainstream media managers themselves, among others, by upholding their commitment to independence, by not taking part in politics or taking sides with certain political forces. The past five years have been called the era of hoaxes and disinformation. The spread of fake news is inseparable from the role of social media as an alternative platform for disseminating information. some of the mainstream media participated in spreading what was circulating in the media about the question without adequate verification.

In countries with a higher democracy index, public data is available on the website of each agency in detail and easy to download. A journalist in London, for example, can obtain data on the location of the incident or the type of crime by downloading or sending electronic mail (e-mail) to the police station. The author's experience as a reporter, requests for data from government agencies, especially at the regional level, are very rare. Every country does have a Public Information Disclosure Law that was passed in 2008, but the instruments provided by the bill are not friendly to journalists. A lawsuit against an agency that refuses to provide public data can take months, even though journalists work with daily or weekly deadlines. Therefore, the mechanism of the law is not the choice of journalists. In fact, even when the lawsuit is granted, the agency requested for data often refuses to submit the data. Even if there is an institution that regularly loads and updates data, generally the data format becomes a problem for the data journalist team to obtain. As a result, the data journalist team had to work longer hours to convert the data format to suit the software used to process the data. As a result, the production process is longer and is considered less efficient by the company. In fact, in a number of media, only additional work for journalists who are already busy with their routine duties. Limitations of Skills If the openness of data is an external factor that becomes an obstacle, the internal factor is more of a limited skill set for journalists who wish to do this. A data journalist, for example, is required to be familiar with numbers and calculations. However, there is a reluctance of some journalists to play with numbers because 
of math aversion. As a result, the ability to analyze data is very limited, even to find interesting issues from a series of numbers.

In addition, in a pandemic situation, framing the news is necessary to maintain a positive perspective from the public towards the government. This will be an important action for the government to solve the pandemic because collaboration between the community and the government is needed. There have been efforts made by the government in fighting COVID19 until finally guaranteed public trust should be the main goal of online news framing in the current pandemic situation.

\section{Conclusion}

Information is an effort to create transparency for the public to find accurate scale information so that the process of conveying the movements that have been carried out by the government or a group of people can provide public trust. Framing the news is necessary to maintain a positive perspective from the public towards the government. This will be an important action for the government to solve the pandemic because collaboration between the community and the government is needed. There have been efforts made by the government in fighting COVID-19 until finally guaranteed public trust should be the main goal of online news framing in a pandemic situation. In the search for alternative information, clashes often arise between what is happening in one media and another. Because people during a pandemic don't just consume one media as a reference for information. The tendency to consume information that is easy to understand and easy to apply in everyday life related to the pandemic has attracted people to choose a media.

\section{References}

Ahmad, A. R., \& Murad, H. R. (2020). The impact of social media on panic during the COVID-19 pandemic in Iraqi Kurdistan: online questionnaire study. Journal of medical Internet research, 22(5), e19556.

Hamzah, F. B., Lau, C., Nazri, H., Ligot, D. V., Lee, G., Tan, C. L., ... \& Chung, M. H. (2020). CoronaTracker: worldwide COVID-19 outbreak data analysis and prediction. Bull World Health Organ, 1(32).

Kane, G. C., Alavi, M., Labianca, G., \& Borgatti, S. P. (2014). What's different about social media networks? A framework and research agenda. MIS quarterly, 38(1), 275-304.

Laroche, M., Habibi, M. R., Richard, M. O., \& Sankaranarayanan, R. (2012). The effects of social media based brand communities on brand community markers, value creation practices, brand trust and brand loyalty. Computers in Human Behavior, 28(5), $1755-1767$.

Liao, Q., Yuan, J., Dong, M., Yang, L., Fielding, R., \& Lam, W. W. T. (2020). Public engagement and government responsiveness in the communications about COVID19 during the early epidemic stage in China: infodemiology study on social media data. Journal of medical Internet research, 22(5), e18796.

Liu, Q., Zheng, Z., Zheng, J., Chen, Q., Liu, G., Chen, S.,\& Ming, W. K. (2020). Health communication through news media during the early stage of the COVID-19 outbreak in China: digital topic modeling approach. Journal of medical Internet research, 22(4), e19118.

Meijer, A. (2009). Understanding modern transparency. International Review of Administrative Sciences, 75(2), 255-269.

Newman, N. (2009). The rise of social media and its impact on mainstream journalism.

Copyright ( 2021, Journal of Asian Multicultural Research for Social Sciences Study, Under the 
Pan, A., Liu, L., Wang, C., Guo, H., Hao, X., Wang, Q., \& Wu, T. (2020). Association of public health interventions with the epidemiology of the COVID-19 outbreak in Wuhan, China. Jama, 323(19), 1915-1923.

Zhao, Y., Cheng, S., Yu, X., \& Xu, H. (2020). Chinese public's attention to the COVID-19 epidemic on social media: observational descriptive study. Journal of medical Internet research, 22(5), e18825. 